\title{
CRISPR system-mediated gene therapy: how flexible it used in genetic diseases
}

\author{
zhixi liu ${ }^{1}$, zhi liao ${ }^{2}$, yan chen $^{1}$, tingwenli huang ${ }^{1}$, lepei zhou ${ }^{1}$, and hongtao xiao ${ }^{1}$ \\ ${ }^{1}$ Sichuan Cancer Hospital and Research Institute \\ ${ }^{2}$ Sichuan Provincial People's Hospital
}

October 28, 2020

\begin{abstract}
Abstract:In the 1960 of the 20th century, scientists firstly advanced the concept of using gene therapy to cure the human genetic disease, which aimed to carry out precisely site-specific modification on the genome for obtain long-term therapeutic effect in patients. In the next 50 years, scientists have developed many new gene editing technologies including zinc-finger nucleases (ZFNs), transcription activator-like effector nucleases (TALENs), and clustered regularly interspaced short palindromic repeats (CRISPR), etc. These new technologies have brought milestone breakthroughs in gene therapy era. In this review, we focus on how flexible the CRISPR system used in human genetic disease-focused research, gene therapy strategies, clinical trials and discuss some of the major challenges and significant benefit for its future use in patients.
\end{abstract}

\section{Hosted file}

manuscript 1.pdf available at https://authorea.com/users/370804/articles/489336-crisprsystem-mediated-gene-therapy-how-flexible-it-used-in-genetic-diseases

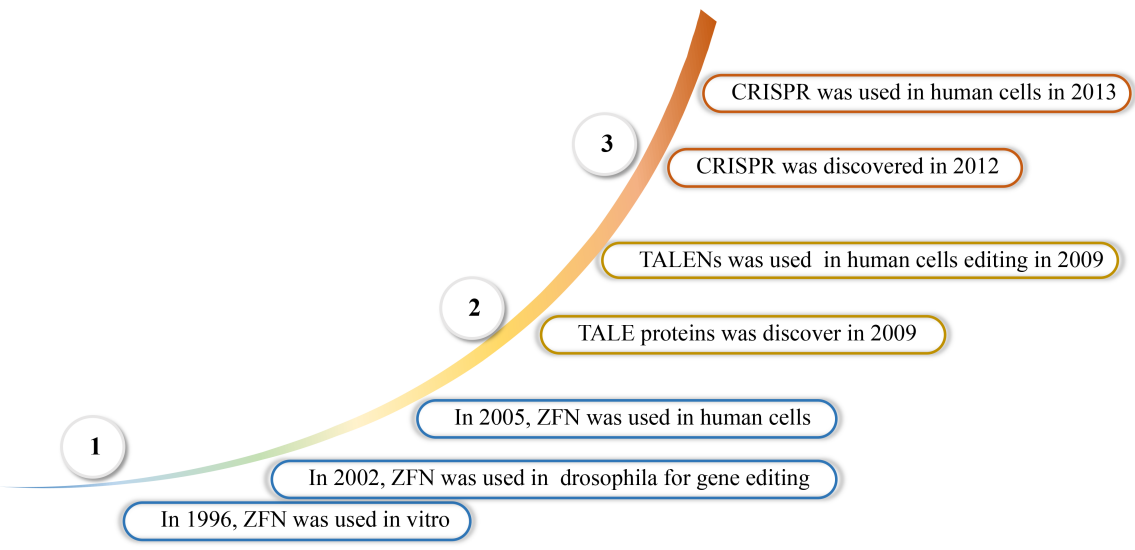




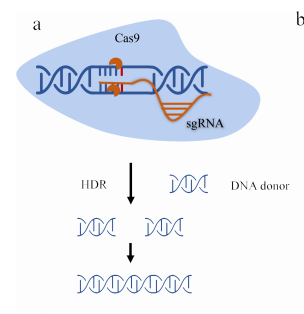

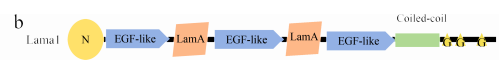

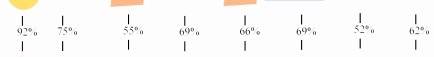

${ }_{\text {INALC }} \approx \approx \approx$

INAS $\longrightarrow \sim \sim$

Ima2 $N$, EGF-like alamA- EGF-like, LamA EGF-like

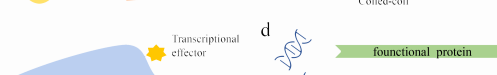

IIIIIS $\simeq \approx \approx$

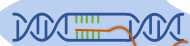

$\underset{\substack{\text { Lamal } \\ \text { promoter }}}{\sigma_{\text {sgRNA }}}$

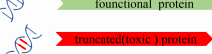

CRISPR system

f

CPISPR

证还

h
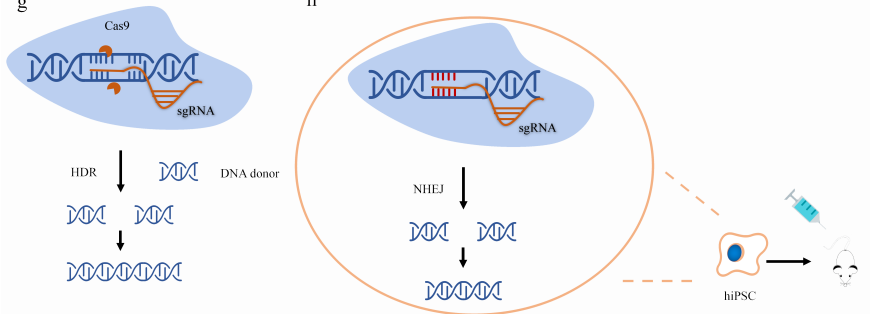